\title{
The Contribution of Adult Education for Community Based Organization: The Case of Bursa Woreda iddirs, SNNP Region
}

\author{
Birhanu Jima \\ Department of Adult Education and Community Development, college of Education and Behavioral Studies. \\ Madda Walabu University Bale Robe Ethiopia \\ Ayele Kumsa \\ Department of Adult Education and Community Development, college of Education and Behavioral Studies. \\ Madda Walabu University Bale Robe Ethiopia
}

\begin{abstract}
The Purpose of this study was to explore the contribution of adult education for the community based organization in Bursa Woreda iddirs. To achieve the purpose; Mixed methods of research design were employed; both quantitative and qualitative data were gathered through questionnaire, interviews and focus group discussion. The iddirs were selected using simple random sampling and the iddirs members and iddirs leader were selected using table of sample size determination following Stratified sampling and availability sampling techniques respectively. The questionnaires were distributed to 120 of respondents. All of the questionnaires $120(100 \%)$ were correctly filled and returned. In addition, 5 of the iddirs member were interviewed. Quantitative data were analyzed using descriptive statistics(percentage, frequency and mean). Qualitative data were analyzed using narrative and thematic description. The major findings revealed that since the introduction of adult education programs with an integrated manner the learners living condition of health care improved, the learners understanding about their rights and responsibilities within the society improved, the learners saving habits and income generation improved. the program develops the learner living together in peace and harmony, the program improved the learners participation in community affairs and their standards of living. the major challenges iddirs do not have capacity building/empowerment programmes and do not have any kind of social or economic empowerment, Therefore, to alleviate these problems, community leaders to ensure their popular participation in educational programme activities that are designed for them to improve their quality of life, strengthening the leaders' knowledge and skills in developmental programmes especially when new innovation in education is made were suggested.
\end{abstract}

Keywords: Iddirs, Integrated, Adult education, community based organization

DOI: $10.7176 / \mathrm{JEP} / 11-19-01$

Publication date:July $31^{\text {st }} 2020$

\section{Background}

Education played big role as a major driver of economic competitiveness in an increasingly knowledge-driven global economy. Contemporary society has high expectations of the contribution that education can make in helping people learn to live with change, to lead change, and to support improvement in all spheres of life (Kala and Chaubey, 2015). Within the community framework, there is need for people to be educated. It is vital because without it, people may not function effectively. Community education is one form of education that will bring about positive change among the people in the community. Ezumah (2004) sees community education as a process aimed at raising consciousness, spreading understanding, and providing the necessary skills, including the human and material resources for the social, economic, political and cultural development. Findsen (2006) defined community education as an organized learning activity that groups or individuals undertake for the personal, community, cultural or economic development. It touches all other areas of learning but its primary focus is the adult as learner and the community as the context. Akande (2007) sees community education as the type of education needed to engender self-confidence, self-respect, and personal independence as well as to safeguard human rights and achieve social equality.

Contextually, community education is the education that promotes the integrated involvement of community members in the effort to bring about desirable social change. It is education for peoples empowerment to take control over their own lives. In other words, it is an educational process whereby people, collectively learn to help themselves and improve their lives. It is the need for improving the quality of life in the community that brought about the activities of community education.

According to Anyanwu (2002), community education is not a new phenomenon of human living. For example, in Nigeria traditional communities, people had been practicing indigenous community education before the advent of the early missionaries and the colonial administration. The traditional apprenticeship programmes were plausible forms of community education. Such programmes were run in the areas of health, agriculture, arts and crafts and constituted a recognized way of inducing enlightenment.

However, formal education alone is not enough to bring rapid and continuous social and economic 
development. It is not also the only means of satisfying the education needs of people. People who do not get the opportunity of formal education should be provided with other alternative ways. One of these alternative ways is non-formal education. There are three modes through which one can gain knowledge. Concerning to this, Aggarwal (2002) expressed them as: formal, non -formal and informal.

Non-formal education according to Ngwu (2003:41) can be defined as: any planned and consciously organized general education and /or training activity outside the formal school in a particular society for illiterates, school leavers, dropouts or other adults, as individuals or in groups, for the purpose of raising their consciousness of their social situation and their standard of living, improving their individual or collective efficiency in their jobs or preparing them for self-employment, wage employment or further training within the existing education/training system.

According to Melkote and Steeves (2001:44), development must improve societal conditions in a sustainable manner. In this regard, Haines (2000:53) mentions that community participation, empowerment, use of indigenous knowledge systems and existing capabilities of people to influence the process of development must all be present. There are many indigenous community based organisations (CBOs), for example, iddirs and other forms of selfhelp groups (SHGs) that have been involved in informal socio-economic development for several decades.

The vast majority of Ethiopia's population lives in the rural areas and are poor, rely on agricultural production for their livelihoods, and suffer from an ever-declining resource base owing to traditional land inheritance patterns. While a successive number of governments have sought to address the needs of the rural poor, only limited improvements have been documented. Rather, community-based development activities have played a larger role for the survival of the rural poor through participation in traditional iddirs (mutual support groups) or self-help groups by using the existing social capital. It was the intent of this research to determine how the social capital incorporated in rural dwellers was transformed into entrepreneurship which, in turn, empowers rural dwellers to create sustainable livelihoods, all in a precarious context that requires risk taking and a paradigm shift in considering personal agency in development. There is no scientific study was conducted on the contribution of adult education for community based organization of the Bursa Woreda Iddirs. In light of the above mentioned reason the researcher would like to conduct this study .

\section{Methods}

\subsection{Research design}

According to James and Sally (2001) descriptive survey is a method which was used to explore relationships between variables and allows generalizations across the population. Therefore, it was used in this study because it enables the researcher to obtain accurate information for large numbers of population using a small sample. A survey design was referred because it concerns itself with describing practices to determine the current status of that population with regard to one or more variables. The usefulness of this design was convenient in collecting extensive quantifiable data from a large sample of respondents within a short period of time

\subsection{Research method}

In this study, mixed method (qualitative and quantitative) with parallel convergent design was used to generate and analyze information obtained from diverse groups of respondents. The quantitative method helps the researcher to analyze the quantitative data obtained through the use of a questionnaire with close-ended question items whereas the qualitative method helps to analyze the data obtained through the use of semi-structured interview guide and focus group discussion (FGD).

\subsection{Data sources}

The data for this study was obtained from both primary and secondary. The primary data for this study was collected from iddirs members and iddirs leaders using questionnaire, FGD and interview. Whereas, secondary data was obtained from documents. These documents include: minutes, centers, policy and strategy documents related to iddirs.

\subsection{Sample and Sampling techniques}

Out of the available 12 iddirs, the following five iddirs were included by using simple random sampling technique: namely, Bursa WoredaTikimt Iddir, Atote Iddir Mahber, Shalom Iddir Mahber, Bursa Ketema Mirael Iddir and Asarado WoyoYemengist Serategnoch Iddir) of Bursa Woreda. With regards to sample the population under the study, out of 385 iddirs members, 115 were selected by using the formula of Cohen et.al (2013). Therefore, the sample size for iddirs members was calculated as follows: $385 \times 30 \%$ So that, $(=115)$. However, 5 iddirs leaders were respondents of this study. The sums of these respondents give rise to 120 subjects.

\subsection{Data collection instruments}

In this study, questionnaire; unstructured interview and focus group discussion. The questionnaires were prepared 
in English language then translated to Amharic and Sidamigna to minimize the language barrier and used to collect data from groups of respondents iddirs members and iddirs leaders. According to Best, (2004), questionnaire was widely used in educational research to obtain information about certain conditions and practices, and inquire into opinions and attitudes of individuals or groups. On the other hands, unstructured interview was employed to collect factual and detail information from Bursa Woreda iddirs leaders. Since the main purpose of interview was to get additional information from responsible bodies, the key content of the questionnaires were included in the interview questions in order to supplement questionnaires responses. In addition, Focus group discussion (FGD) were used to triangulate information obtained by using other data collection instruments and watching to an interaction or phenomenon as it takes place respectively.

\subsection{Methods of data analysis.}

In this study the response that was obtained from questionnaire, interview and focus group discussion were organized, summarized and analyzed qualitatively and quantitatively. To analyze the quantitative data for example, the data gathered through close ended questions was first presented in the tables and statistically analyzed. On the other hand, the collected data was coded and analyzed using SPSS-20. Quantitative data were analyzed using percentage, frequency and mean. Qualitative data were analyzed systematically using narrative and quotation approach to substantiate quantitative analysis.

\section{Result}

\subsection{Socio demographic characteristics of the respondents}

The major demographic characteristics of respondents include sex, age, marital status, educational level and their work of experiences.

Table 4.1 Socio demographic characteristics of the respondents

\begin{tabular}{|c|c|c|c|c|c|c|}
\hline \multirow[t]{2}{*}{ R.No. } & \multicolumn{2}{|c|}{ Variables } & \multicolumn{2}{|c|}{ Iddirs members } & \multicolumn{2}{|c|}{ Iddirs leaders } \\
\hline & & & No & $\%$ & No & $\%$ \\
\hline \multirow[t]{2}{*}{1} & Sex & Male & 34 & 28.33 & 3 & 60 \\
\hline & & Female & 86 & 71.67 & 2 & 40 \\
\hline \multirow[t]{4}{*}{2} & Age & Below 20 & 43 & 35.8 & 3 & 60 \\
\hline & & $21-30$ & 58 & 48.33 & 1 & 20 \\
\hline & & $31-40$ & 16 & 13.33 & 1 & 20 \\
\hline & & Above 40 & 4 & 3.33 & & \\
\hline \multirow[t]{3}{*}{3} & Marital status & Single & 48 & 40 & 3 & 60 \\
\hline & & Married & 68 & 56.67 & 2 & 40 \\
\hline & & Divorced & 4 & 3.33 & & \\
\hline \multirow[t]{3}{*}{4} & Education level & Level one & & & & \\
\hline & & Level two & 115 & 100 & & \\
\hline & & $10-12$ & & & 5 & 100 \\
\hline \multirow[t]{3}{*}{5} & Work experience & $1-5$ & & & 5 & 100 \\
\hline & & $6-10$ & & & & \\
\hline & & $11-20$ & & & & \\
\hline \multicolumn{2}{|c|}{ Total Population } & & 115 & & 5 & \\
\hline
\end{tabular}

Source: Field survey, 2019

As indicated in table 1 above, a total of 120 respondents of Iddirs members and Iddirs leaders were included in the study. $34(28.33 \%)$ respondents were males while the remaining $86(71.67 \%)$ are females. The researcher sampled proportion of respondents by sex proportion of their enrollment.

The findings showed that the female participation in adult education program is by far more than that of the males. This implies that the participation of women's in the program is at better condition (level). This confirms that the case in focusing ESDP V adult and non-formal education program resources on increasing female participation and completion rates seem to be improved at shashemene City Administration. Of the target 19.4 million illiterate adults targeted by the program, 12.4 million (64\%) are female (MoE, 2015).

Regarding item 2, table 1 the age of respondents both the Iddirs members and Iddirs leaders, $46(36.8 \%)$ respondents were in the age group of below 20 years. The others $59(47.2 \%)$ respondents were between the age group of 21-30 years. Thus the majority of the respondents were in this age group. $16(13.33 \%)$ respondents were between the age group of 31-40 years. and the rest very few $4(3.33 \%)$ respondents were in the age group of above 40 years. This revealed that most of iddirs members were with the center of productive age range between 15 and 60 were young and energetic. Working with this age group is working on the country development program.

Regarding item 3, table 1 the marital status of the respondents were 51(40.8\%) of iddirs member and iddirs leader were single, while $70(56 \%)$ of iddirs member and iddirs leader, were married. Whereas $4(3.33 \%)$ of the iddirs member were divorced. This revealed that the respondents have been working and have family 
responsibility

Educational level of iddirs member and iddirs leader $125(100 \%)$ were level two and they were able to read and write.

Regarding item 5, table 1 the experience of iddirs member, most of them had a work experience ranging between one and five years. This revealed that there was a shortage of more experienced iddirs leader.

3.2. Issue related to the contribution of the adult education to socio-economic status of the learners. Table 2:- Iddirs member and Iddirs leader response based on the contribution of AE to socio- economic status of the learners.

\begin{tabular}{|c|c|c|c|c|c|c|c|}
\hline Variables & Resp. & $\mathbf{N}$ & $\mathbf{A}$ & UD & DA & Mean & SD \\
\hline $\begin{array}{l}\text { 1. Literacy skills enhanced me } \\
\text { saving habit. }\end{array}$ & $\begin{array}{l}\text { IM } \\
\text { IL }\end{array}$ & $\begin{array}{l}115 \\
5\end{array}$ & $\begin{array}{l}105(95.5 \%) \\
8(80 \%)\end{array}$ & 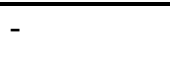 & $\begin{array}{l}5(4.5 \%) \\
2(20 \%)\end{array}$ & 4.7333 & .67030 \\
\hline $\begin{array}{l}\text { 2. IFAE skills helped me to } \\
\text { generate the income. }\end{array}$ & $\begin{array}{l}\text { IM } \\
\text { IL } \\
\text { IL }\end{array}$ & $\begin{array}{l}115 \\
5 \\
5\end{array}$ & $\begin{array}{l}100(90.9 \%) \\
7(70 \%) \\
7(70 \%)\end{array}$ & $2(20 \%)$ & $\begin{array}{l}10(9.1 \%) \\
1(10 \%) \\
3(30 \%)\end{array}$ & 4.5917 & .87443 \\
\hline $\begin{array}{l}\text { 3. The program enhanced } \\
\text { people's capacity to resolve the }\end{array}$ & $\begin{array}{l}\text { IM } \\
\text { IL }\end{array}$ & $\begin{array}{l}115 \\
5\end{array}$ & $\begin{array}{l}95(86.4 \%) \\
9(90 \%)\end{array}$ & & $\begin{array}{l}15(13.6 \%) \\
1(10 \%)\end{array}$ & 4.4167 & 1.00906 \\
\hline & IL & $J$ & $7(70$ & & $3(3$ & & \\
\hline $\begin{array}{l}\text { 4. IFAE training helped to living } \\
\text { together in peace and harmony . }\end{array}$ & $\begin{array}{l}\text { IM } \\
\text { IL }\end{array}$ & $\begin{array}{l}115 \\
5\end{array}$ & $\begin{array}{l}80(72.7 \%) \\
7(70 \%)\end{array}$ & $\begin{array}{l}20(18.2 \%) \\
2(20 \%)\end{array}$ & $\begin{array}{l}10(9.1 \%) \\
1(10 \%)\end{array}$ & 4.5500 & .87783 \\
\hline $\begin{array}{l}\text { 5. Literacy skills expand } \\
\text { people's expectation for leading } \\
\text { better quality of life. }\end{array}$ & $\begin{array}{l}\text { IM } \\
\text { IL }\end{array}$ & $\begin{array}{l}115 \\
5\end{array}$ & $\begin{array}{l}101(91.8 \%) \\
8(80 \%)\end{array}$ & & $\begin{array}{l}9(8.2 \%) \\
2(20 \%)\end{array}$ & 4.5917 & .83511 \\
\hline $\begin{array}{l}\text { 6. IFAE training improved social } \\
\text { participation in community } \\
\text { affairs. }\end{array}$ & $\begin{array}{l}\text { IM } \\
\text { IL }\end{array}$ & $\begin{array}{l}115 \\
5\end{array}$ & $\begin{array}{l}100(90.9 \%) \\
9(90 \%)\end{array}$ & & $\begin{array}{l}10(9.1 \%) \\
1(10 \%)\end{array}$ & 3.9667 & 69733 \\
\hline $\begin{array}{l}\text { 7. IFAE training improved the } \\
\text { parents to encourage and send } \\
\text { their children to school. }\end{array}$ & $\begin{array}{l}\text { IM } \\
\text { IL }\end{array}$ & $\begin{array}{l}115 \\
5\end{array}$ & $\begin{array}{l}90(81.8 \%) \\
8(80 \%)\end{array}$ & $\begin{array}{l}10(9.1 \%) \\
1(10 \%)\end{array}$ & $\begin{array}{l}10(9.1 \%) \\
1(10 \%)\end{array}$ & 4.6333 & .88814 \\
\hline $\begin{array}{l}\text { 8. IFAE training improved } \\
\text { understanding about their rights } \\
\text { and responsibilities within the } \\
\text { society. } \\
\text { Average grand Mean }\end{array}$ & $\begin{array}{l}\text { IM } \\
\text { IL }\end{array}$ & $\begin{array}{l}115 \\
5\end{array}$ & $\begin{array}{l}84(76.4 \%) \\
7(70 \%)\end{array}$ & $\begin{array}{l}16(14.5 \%) \\
2(20 \%)\end{array}$ & $\begin{array}{l}10(9.1 \%) \\
1(10 \%)\end{array}$ & 4.6167 & .86173 \\
\hline
\end{tabular}

Source: Field Survey December, 2019

NB: Analysis interval of mean score: 1.0--2.5=Disagree, $2.51-3.5=$ Undecided, 3.51--5.0=

Agree ,IM= Iddirs member, $\mathbf{I L}=$ Iddirs leader

To analyze this data the researchers merged Strongly Agree and Agree = "Agree", Disagree and Strongly Disagree $="$ Disagree"

Regarding items 1-8 of table 2, most of the respondents (Iddirs members and Iddirs leaders) confirmed that adult education played pivotal role in socio-economic contribution to the Iddirs members of adult education learners and improved AE learners saving habits, enable the learners to plan and participates in income generation and proper decision making, improve the learners capacity to resolve the conflict peacefully, improve the learners to living together in peace and harmony, enables the learners to expand their expectation for leading better quality of life, improved participation in community affairs and their standards of living, improve the parents to encourage and send their children to school, improved their understanding about their rights and responsibilities within the society.

In relation to this, Okech (2009) underpinned that adult education contributes to economic empowerment particularly by enabling adult education learners to make their goods more effectively and that enable them to plan and participates in income generation and proper decision making. In addition to this, participants of adult education were equipped with essential literacy and numeracy skills through this program, sickness and mortality rates of children and mothers reduced and then increased their life expectancy, improved their understanding about their rights and responsibilities within the society, improved societal participation on environmental protection practice (natural resource conservation) and improved personal and community hygiene. The average grand combined mean score of all items was 4.53 which indicated that the contribution of the adult education to socioeconomic status of the learners in the above listed items were high. Likewise, during interview session with one of the Iddirs leader: "He replied that adult learners in Bursa Woreda have achieved significant change in 
participation in community affairs and their standards of living, improved their saving habits and understanding about their right and responsibilities within the community".(December,2019).

3.3 Issue related the to what extent do community based organizations leaders need basic education? Table 3: Iddirs member and Iddirs leader response based on Mean of the basic education needs of the respondents

$\mathbf{N}=\mathbf{1 2 0}$

\begin{tabular}{lllll}
\hline \multicolumn{1}{c}{ No } & Variables & $X$ & SD & Decision \\
\hline 1 & Basic literacy skills i.e. ability to read, write, and compute figures & 3.72 & .476 & Accepted \\
2 & Simple hygiene and other health care practices & 3.46 & .542 & Accepted \\
3 & Nutritional values of balancing daily diet & 3.41 & .553 & Accepted \\
4 & New Methods of farming & 3.40 & .629 & Accepted \\
5 & Civic education & 3.47 & .569 & Accepted \\
Overall & & $\mathbf{3 . 4 9}$ &. $\mathbf{2 8 8}$ & Accepted \\
\hline
\end{tabular}

Source: Field Survey December, 2019

Table 3 shows that items 1-5 have mean ratings of 3.72, 3.46, 3.41, 3.40 and, 3.47, respectively. Each of these items has mean rating that is greater than the criterion mean of 2.50 . Also, the table shows the overall mean of 3.49 which is greater than the criterion mean. This, therefore, implies that the respondents agreed that they need basic education which includes basic literacy, simple hygiene and health care, family planning, social change, nutritional values, new methods of farming to improve their quality of life.

\subsection{Issue related to How is empowerment related to entrepreneurship in iddirs?}

Table 4:- Iddirs member and Iddirs leader response based on how is empowerment related to entrepreneurship in iddirs?

\begin{tabular}{lllll}
\hline Variables & \multicolumn{3}{l}{ Yes } & \multicolumn{3}{l}{ No } \\
\cline { 2 - 6 } & $\mathrm{f}$ & $\%$ & $\mathrm{f}$ & $\%$ \\
1. Does your iddir have capacity building/training programmes for its members & 5 & 4 & 115 & 96 \\
2. Does iddirs members' involvement in social and economic & 50 & 41.7 & 70 & 58.3 \\
decision making? & & & \\
3. Are you involved in any entrepreneurial activities other than regular farming? & 62 & 52 & 58 & 48 \\
4. Does your self help group(SHG) have a microcredit program & 76 & 63.2 & 44 & 36.8 \\
\hline
\end{tabular}

Source: Field Survey Decembere, 2019

Regarding items 1 of table 4 , Of the total sample of respondents who were asked about the condition of iddirs' capacity building, $115(96 \%)$ responded that iddirs do not have capacity building/empowerment programmes, while only $5(4 \%)$ indicated that they do. Three iddir focus groups, namely the Bursa WoredaTikimt Iddir, Atote Iddir Mahber, Shalom Iddir Mahber and Bursa Ketema Mirael Iddir were asked about capacity building. They confirmed that their iddirs do not have any kind of social or economic empowerment, besides the Bursa Ketema Mirael iddir focus-group respondents who mentioned that their leaders once attended an HIV/AID awareness creation workshop. In this connection, one of the Atote Iddir Mahber focus group respondents' stated:

"I am an old man and a member of iddir all my life. But, I have not seen any endeavours to assist members in daily livelihood struggle, besides assisting during funeral ceremony. The poor are already dead while alive because of destitution. Iddir could have assisted the poor, if involved in poverty alleviation program". (December, 2019).

Regarding items 2 of table 4 , to assess the condition of iddirs empowerment from another dimension, the respondents were asked about iddirs members' involvement in social and economic decision making. $70(58.3 \%)$ of the respondents said that decisions are being made by the leadership only and 50(41.7\%) said that members are also included in decision-making. This is an expected trend because in many places iddir leaders are prominent figures in the community and members respect the leaders' decisions. However, this does not indicate the members' satisfaction concerning the decision-making process.

Regarding items 3 of table 4, Respondents were asked about the condition of entrepreneurship: $62(52 \%)$ responded that iddirs members are not involved in any other entrepreneurial or income generation activities besides farming, 58(48\%) reported they are involved in other entrepreneurial activities. Entrepreneurship development and microfinance service has become the lifeline for socio-economic development and poverty alleviation in many developing countries, particularly Ethiopia. Entrepreneurship promotion rests on social capital. Iddirs' activities are collective and could promote other livelihood activities if adjusted in that manner. Bearing this in mind, a field survey was conducted to see the extent of iddirs' involvement in entrepreneurship promotion and micro-credit service provision.

Regarding items 4 of table 4, respondents were also asked about microcredit service. Of the 
respondents,76(63.2\%) reported the absence of microcredit service, while 44(36.8\%) indicated that the service is available.

\section{Discussion}

The findings showed that the female participation in adult education program is by far more than that of the males. This implies that the participation of women's in the program is at better condition (level). This confirms that the case in focusing ESDP $\mathrm{V}$ adult and non-formal education program resources on increasing female participation and completion rates seem to be improved at Bursa Woreda. Of the target 19.4 million illiterate adults targeted by the program, 12.4 million (64\%) are female (MoE, 2015).

Regarding age of respondents the majority of the respondents were between the age group of 21-30 years. This revealed that most of iddirs members were with the center of productive age and Working with this age group is working on the country development program.

\section{The contribution of $\mathrm{AE}$ to socio-economic status of the learners}

According to the answers which were given by the participants, AE played pivotal role in socio-economic contribution to the iddirs member of $\mathrm{AE}$ learners and improved iddirs member AE learners saving habits, enable the learners to plan and participates in income generation and proper decision making, improve the learners capacity to resolve the conflict peacefully, improve the learners to living together in peace and harmony, enables the learners to expand their expectation for leading better quality of life, improved participation in community affairs and their standards of living, improve the parents to encourage and send their children to school, improved their understanding about their rights and responsibilities within the society.

\section{The extent to community based organizations leaders need basic education}

According to the answers which were given by the participants, that the respondents agreed that they need basic education which includes basic literacy, simple hygiene and health care, family planning, social change, nutritional values, new methods of farming to improve their quality of life.

\section{How is empowerment related to entrepreneurship in iddirs?}

Based on the analysis, the finding confirmed that; iddirs do not have capacity building/empowerment programmes and do not have any kind of social or economic empowerment, in many places iddir leaders are prominent figures in the community and members respect the leaders' decisions, however, this does not indicate the members' satisfaction concerning the decision-making process, iddirs members are not involved in any other entrepreneurial or income generation activities and absence of microcredit service.

\section{CONCLUSIONS}

Based on the major findings, the following conclusions were drawn. The major objective of the study was to explore the contribution of adult education for the community based organization in Bursa Woreda iddirs. The practice of adult education has been benefited considerable number of adults live in the Bursa Woreda. Their understanding about their saving habits, enable the learners to plan and participates in income generation and proper decision making, improve the learners capacity to resolve the conflict peacefully, improve the learners to living together in peace and harmony, enables the learners to expand their expectation for leading better quality of life, improved participation in community affairs and their standards of living, improve the parents to encourage and send their children to school, improved their understanding about their rights and responsibilities within the society, improved their understanding about their hygiene and health care, family planning, social change, nutritional values, new methods of farming to improve their quality of life.

However, finding confirmed that; iddirs do not have capacity building/empowerment programmes and do not have any kind of social or economic empowerment, in many places iddir leaders are prominent figures in the community and members respect the leaders' decisions, however, this does not indicate the members' satisfaction concerning the decision-making process, iddirs members are not involved in any other entrepreneurial or income generation activities and absence of microcredit service.

\section{RECOMMENDATIONS}

Based on the preceding findings and conclusions the following recommendations were forwarded:

Since the outcome of the program(adult education) contributed to the socio- economic status individuals and the community as whole, political leaders, professionals, nongovernmental organizations and responsible bodies should participate and support the implementation of the program in order to improve the iddir learners' socioeconomic change.

The Education Office for mass literacy, adult and non-formal education in Bursa Woreda shall be mount campaign in the rural communities on the need for community education programmes. This is to sensitize community leaders to ensure their popular participation in educational programme activities that are designed for them to improve their quality of life. The government shall from time to time organize workshops, seminars, and symposium for community leaders and adult educators. 
This will go a long way in strengthening the leaders' knowledge and skills in developmental programmes especially when new innovation in education is made.

The researcher recommended that the self help groups(SHGs) and iddirs empowerment should entail sustainable development and livelihood finance in order to make sustainable livelihoods real. Without such an integrated and systematic approach sustainable livelihoods could be an illusion.

\section{Acknowledgment}

The authors are grateful for the valuable guidance from two anonymous reviewers. The author is also thankful to Bursa Woreda all adult education practitioners' who have supported and/or inspired this work through the various support. Finally, this research did not receive any specific grant from funding agencies in the public, commercial, or not-for-profit sectors.

\section{Conflict of interest}

The author(s) declared no potential conflicts of interest with respect to the research, authorship, and/or publication of this article. And we need to ensure that we are responsible for any conflict of interest that may arise. Also we have not received any fee for patents for the manuscript. Concerning non-financial computing interest the authors encourage the manuscript has significant value for intellectual and/or academic purposes.

\section{Outer's contribution}

Birhanu Jima: Corresponding authors from Department of Adult Education and Community Development, college of Education and Behavioral Studies. He published two journals. He worked a lot so as to prepare and manuscript. He worked a lot from data collection up to analysis, conclusion and recommendation

Ayele Kumsa: is an assistant professor in department of Department of Adult Education and Community Development, college of Education and Behavioral Studies. He worked for four years as a lecturer and AECD department Head. He contributed a lot for this manuscript. He guide the way to re arranged manuscript. He edited the manuscript before submission. Furthermore, he played a great role in finding recent reputable journal publishers

\section{References}

Aggrawal. (2002). Recent development and trandes in Education. New Delhi Shipra Puplication

Akande, J.O. (2007). The Practice of community Education in Nigeria.Educational Research and Review, 2 (10), 264-270.

Ani, R.O.(2003). An introduction approach to the study of adult education.Enugu: Donsimbad Communications. Anyanwu, C.N. (1999). Introduction to community development.Ibadan: Gabesther Educational Publishers.

Anyanwu, C.N. (2002). Community education: The African Dimension. Ibadan: Alafas Nigeria Company.

Best. (2004). Research in Education.New Jersey Orentice Hall.

Clark, J. 2000. Civil Society, NGOs and development in Ethiopia. Washington D.C. World Bank.

Dublin Declaration (1983).Community education. In C.N. Anyanwu (Ed), Community education: The African dimension (p.86). Ibadan: Alafas Nigerian Limited.

Ezumah, M.O.A. (2004). Knowing adult education: Its natureScope, and processes. Owerri:Spring Field Publishers Ltd.

Findsen, B. (2006). Assess and Participation issues in New Zealand adult, community, and tertiary education as social justice. In A.B. Oduaran and H.S. Bhola (eds), Wideningaccess to education as social justice. Netherland: Springer.

Hildana, G. (2014). Practice and Challenges of IFALP: The case Of Kolfe Keranyo Sub City. Addis Ababa.

James, O. and Sally, A. (2001). A study in the problems of Harnessing community and Education in Tanzania. Dere Salaam:Makerere University.

Kothari. (2004). Research Methodology ,method and techniques.(2nd ed.New delhi Age instructiona.

Mengesha, ST. 2002.The role of civil society organisations in poverty alleviation,sustainable development and change: the case of iddirs in Akakki, Nazerate and AddisAbaba.

MA Thesis.Graduate school of Addis Ababa University.

Mequanent, G. 2009. The two sector civil society in Ethiopia. Available at: http://www.aigaforum.com/.../TwoSector-Civil-Society.htm (accessed 21/8/2010).

Ngwu, P.N.C. (2003). Non-formal education: Concepts and practices. Enugu: Fulladu Publishing Company.

Pankrurst, A. 1998.Towards an understanding of associative society: characteristics, potentials, constraints. Addis Ababa University: Addis Ababa.

Solomon, D.1999. Micro credit though community based organisations: the experienceof

Wikipedia, the free encyclopedia (2012).Meaning of community based organizations. Retrieved on 10th February 2013 from http://en.wikipedia.org/wikicommunity_organization. 